\title{
Climate change increases risk of fusarium ear blight on wheat in central China
}

X. Zhang ${ }^{1,2,3,4}$, J. Halder ${ }^{5}$, R. P. White ${ }^{3}$, D. J. Hughes ${ }^{1}$, Z. Ye ${ }^{2}$, C. Wang ${ }^{6}$, R.

$\mathrm{Xu}^{7}$, B. $\operatorname{Gan}^{8}$ \& B. D. L. Fitt ${ }^{1,3}$

1 University of Hertfordshire, Hatfield, Hertfordshire, AL10 9AB, UK

2 Elementary Education College, Chongqing Normal University, Chongqing, 400700, China

3 Rothamsted Research, Harpenden, Hertfordshire, AL5 2JQ, UK

4 Southwest University, Chongqing, 400715, China

5 School of Public Health, Imperial College, London, W2 1PG, UK

6 Hadley Centre, Met Office, Meteorology Building, University of Reading, Reading, RG6 6BB, UK

7 Hubei Plant Protection Station, Wuhan, Hubei, 430070, China

8 Crop Research Institute, Anhui Academy of Agricultural Sciences, Hefei, Anhui, 230000,

China

\section{Correspondence}

B. D. L. Fitt, University of Hertfordshire, Hatfield, Hertfordshire, AL10 9AB, UK.

Email: b.fitt@herts.ac.uk

\section{Abstract}

To estimate potential impact of climate change on wheat fusarium ear blight, simulated weather for the A1B climate change scenario was imported into a model for estimating fusarium ear blight in central China. In this work, a logistic weather-based regression model for estimating incidence of wheat fusarium ear blight in central China was developed, using up to 10 years (2001-2010) of disease, anthesis date and weather data available for 10 locations in Anhui and Hubei provinces. In the model, the weather variables were defined with respect to the anthesis date for each location in each year. The model suggested that incidence of fusarium ear blight is related to number of days of rainfall in a 30-day period after anthesis and that high temperatures before anthesis increase the incidence of disease. Validation was done to test whether this relationship was satisfied for another five locations in Anhui province with fusarium ear blight data for 4 to 5 years but no nearby weather data, 
using weather data generated by the regional climate modelling system PRECIS. How climate change may affect wheat anthesis date and fusarium ear blight in central China was investigated for period 2020-2050 using wheat growth model Sirius and climate data generated by PRECIS. The projection suggested that wheat anthesis dates will generally be earlier and fusarium ear blight incidence will increase substantially for most locations.

\section{Keywords}

Climate change impacts; food security; logistic regression model; sustainable agriculture; weather-based disease forecasting; wheat fusarium ear blight.

\section{Introduction}

Fusarium ear blight (FEB) (also known as fusarium head blight or scab; www.scabusa.org), which is caused by several fungal species with Fusarium or Fusarium-like anamorphs, is a serious disease of wheat in many areas of the world (Parry et al., 1995; Goswami \& Kistler, 2004; West et al., 2012). Where severe epidemics occur, losses in grain yield are frequently $30 \%$ and may be as much as 60\%; in the USA it was estimated that FEB on wheat and barley caused more than $\$ 6$ billion of losses in the period 1991-1997 (Parry et al., 1995; Ma et al., 2009). Furthermore, the mycotoxins produced by the Fusarium species associated with FEB increase the threat to food security posed by FEB epidemics (Franz et al., 2009; SchmidtHeydt et al., 2011). In China, the country which has one of the largest areas of wheat grown in the world (c. $24 \mathrm{M}$ ha), including both winter wheat and spring wheat, FEB is mainly caused by Fusarium graminearum and F. asiaticum (Qu et al., 2008). The most serious epidemics of FEB are mainly in the winter wheat growing region (c. $7 \mathrm{M} \mathrm{ha}$ ) in central China (Figure 1) including Anhui and Hubei provinces and in a small region in the northeast where spring wheat is growing (http://www.nal.usda.gov/pgdic/WHS/intro.html). In a world where more than 1 billion people currently do not have enough to eat (Anonymous, 2009; Mahmuti et al., 2009) and food security is threatened by population growth and climate change (Beddington, 2010), it is essential to improve control of crop diseases like FEB, both in China and elsewhere.

(Figure 1 near here)

Climate change may have direct or indirect impacts on crop yield (Roudier et al., 2011; Stratonovitch et al., 2012) and the severity of crop disease epidemics. It has direct impacts on severity of epidemics of diseases such as FEB in wheat and phoma stem canker in oilseed 
rape because weather factors influence the progress of disease epidemics (Evans et al., 2008; West et al., 2012). Regional and seasonal variation in weather greatly influences severity of FEB (Rossi et al., 2003). The disease is monocyclic (one disease cycle per cropping season) because wheat is susceptible to infection only for a short period at anthesis, if deposition of pathogen spores on exposed anthers coincides with warm, wet weather that favours infection (Paul et al., 2007; Xu et al., 2007). Thus, to estimate the direct impacts of climate change on epidemic severity it is essential to include the impact of weather on crop development, since weather influences rate of crop development (e.g. anthesis date) (Butterworth et al., 2010; Madgwick et al., 2011). For example, by inputting simulated weather for different climate change scenarios into a suitable weather-based FEB model, based around estimates of anthesis date derived from the Sirius wheat crop growth model (Jamieson et al., 1998), it was predicted that climate change will increase the incidence of FEB in the UK (Madgwick et al., 2011). There is a need to obtain similar estimates for China, firstly by developing an appropriate weather-based model for predicting severity of FEB epidemics there.

Weather variables in time periods close to anthesis have been used to construct weatherbased models to forecast FEB epidemic development in countries such as Argentina, the USA, Italy, Brazil and the UK (Moschini et al., 2001; De Wolf et al., 2003; Rossi et al., 2003; Del Ponte et al., 2005; Madgwick et al., 2011) but not in China. However, none of these existing models developed for other countries fitted Chinese data well. For example, if Chinese weather data was substituted into the two Argentinian models (Moschini et al., 2001), most of the predicted values of incidence (\% ears affected with FEB) were much greater than the observed values (Supplementary Figure 1; data for other models not presented). This was not unexpected since disease-weather relationships vary geographically. Therefore, there is a need to develop a China-specific weather-based model for predicting FEB epidemic severity and testing the hypothesis that climate change will directly increase the incidence of crop diseases, using wheat fusarium ear blight as an example.

It is difficult to estimate indirect impacts of climate change on crop disease epidemics. For FEB, these indirect impacts include impacts on crop rotations, such as the frequency of maize, since grain maize as the previous crop in the rotation greatly increases FEB risk because maize debris is a potent source of F. graminearum inoculum (West et al., 2012; Xu \& Nicholson, 2009). Increasing temperature favours the growth of maize, which is already grown widely in China (cf. the UK where maize-wheat rotations are not common but may increase with increasing temperature). However, since agronomic decisions are not solely a consequence of changing climate, indirect impacts of climate change on FEB risk will not be 
considered. Thus, this paper describes work to identify the weather variables associated with FEB epidemic development in central China. Then combine these relationships with a wheat crop growth model and with climate change projections to estimate the direct impact of climate change on risk of epidemics.

\section{Materials and methods}

Collation of data for FEB, winter wheat date of anthesis and weather for locations in Anhui and Hubei provinces, China

To project the impacts of climate change on the severity of FEB epidemics, firstly observed data were used to develop a weather-based model for FEB in China. Thus, observed FEB, anthesis date and weather data were collated (Figure 2). Wheat FEB data had been collected from commercial wheat crops at 15 locations in Hubei and Anhui provinces, central China, for between 3 and 10 years per location from 2001 to 2010, by the Hubei and Anhui Plant Protection Stations (Supplementary Table 1). At each location, there were disease data for 1-6 winter wheat cultivars, planted as commercial crops on which fungicide had not been used. Thus, data for each location from several different crops about 5-10 km apart from each other were recorded as the mean value for that location. These FEB data included measurements of disease incidence (percentage of ears affected by FEB), disease severity (measured on a scale $i, i=1,2,3,4,5)$ and disease index (calculated from severity: $100 \Sigma\left(i n_{i}\right) /\left(\max \{i\} \Sigma n_{i}\right), i=1,2$, $3,4,5$, where $i$ was the severity value and $n_{i}$ the number of the ears with disease severity $i$ ). These disease data were measured regularly every 3 to 5 days between anthesis (April) and harvest (May, about 30 days after anthesis) and a mean value for all the cultivars at the location was calculated without assessing differences between cultivars.

(Figure 2 near here)

Data for the dates of anthesis of winter wheat cultivars (mid-anthesis is growth stage 65 on the Zadoks scale, Lancashire et al., 1991) in the commercial winter wheat crops were provided for all 15 locations by the Crop Research Institute of the Anhui Academy of Agricultural Sciences of China. Since different cultivars with different anthesis dates were grown at each location, the anthesis dates were recorded as both a range of dates and a mean date for each location. 
For five of the locations in Anhui province (Tongcheng, Nanqiao, Lu'an, Fengtai and Fengyang), there were also available detailed records from experimental field trials for sowing date, anthesis date and maturity date (growth stage 89) for eight cultivars (Yangmai 158, Yangmai 00126, Annong 95081-8, Fumai 9606, Yangmai No.11, Yangfumai 5242, Wanmai 606, Wanmai 202) for at least two successive years during the period 2001-2010. In these experimental fields at these five locations, the different winter wheat cultivars were planted as breeding lines. These detailed data were used for calibration of the wheat growth model Sirius anthesis date (Jamieson et al., 1998).

The weather data extracted from the China Meteorological Data Sharing Service System included daily minimum, maximum and mean temperature $\left({ }^{\circ} \mathrm{C}\right)$, total rainfall $(\mathrm{mm})$, relative humidity (\%) and sunshine duration (hours, can be converted into daily solar radiation $\left(\mathrm{W} / \mathrm{m}^{2}\right.$ ) using latitude of the location and some other information). Out of the 15 locations in Anhui and Hubei provinces with FEB and anthesis date data, there were six locations with weather stations closer than $5 \mathrm{~km}$, another two locations with weather stations closer than $20 \mathrm{~km}$ and another two locations with weather stations closer than $30 \mathrm{~km}$ (Supplementary Table 1). Therefore, there were 10 locations with disease data, anthesis date data and weather data for continuous periods of 3 to 10 years, which could be used for model construction, giving 70 sets of observations.

\section{Construction of weather-based model for FEB}

For the 10 locations with disease, anthesis date and weather data for continuous periods of 3 to 10 years, the relationships between the incidence and severity (index) of FEB were examined and the most appropriate disease variable for constructing the weather-based model was selected. Many studies indicate that the severity of FEB epidemics is related to temperature and rainfall patterns (Chakraborty et al., 2000; Xu et al., 2007) and that wheat is susceptible to infection for only a short period near anthesis date (Xu \& Nicholson, 2009). Hence the weather variables selected for testing were daily mean temperature $(T)$, daily maximum temperature $(m T)$, daily total rainfall $(R)$, daily relative humidity $(H)$ and number of days with $\geq 0.1 \mathrm{~mm}$ rainfall $(N R)$. Weekly and monthly mean values of $T, m T, R$ and $H$ and weekly and monthly sums of $N R$ were calculated for periods up to 8 weeks before and after the mean anthesis date at each of the 10 locations in every year. This gave 100 weather variables to be tested, firstly alone and then in combinations of two variables by choosing one 
of the 10 variables with the best results in the first round to combine all the others one by one, using maximum likelihood and step-wise regression in GENSTAT ( Payne et al., 2011).

\section{Generation and validation of weather and climate data for different climate scenarios (PRECIS)}

Weather data (maximum temperature, mean temperature, total rainfall and solar radiation $\left.\left(\mathrm{W} / \mathrm{m}^{2}\right)\right)$ specific to all 15 locations located in Anhui and Hubei provinces (altitude, latitude and longitude, Supplementary Table 1) for 2001-2008 were obtained from downscaled ERAINTERIM global atmospheric reanalysis (Dee et al., 2011) using the regional climate model PRECIS developed by the Hadley Centre (Jones et al., 2004) at a horizontal resolution of $50 \mathrm{~km}$.

Daily weather outputs were obtained from a climate projection using PRECIS to downscale a global climate model projection HadCM3 (a coupled ocean-atmosphere global climate model developed at the Hadley Centre, Gordon et al., 2000, which included greenhouse gas concentrations and sulphate emissions from the SRES A1B emissions scenario, Nakicenovic et al., 2000, for the period 2020-2050). It is important to note that this information on future climate was generated using a single global and regional climate model coupling and that it represents one plausible future climate. There is reasonable confidence in the projected temperature changes in this climate scenario but less confidence in changes in precipitation and other variables (Christensen et al., 2007).

This climate projection was used to assess the risk of FEB on wheat under climate change in Central China. The outputs from PRECIS for daily mean temperature, maximum temperature, rainfall and radiation for 2001 - 2008 were validated by comparing them with observed data for those locations for which observed weather data were available. Since the PRECIS data were to be used as inputs for operating the wheat crop growth model Sirius and the FEB model, to allow mean anthesis date and thus mean FEB incidence to be generated, a comparison was needed between projected weather data for 2020-2050 and past/present weather data. For a meaningful comparison to be made, it was necessary to have data sets of comparable size. Since observed weather data were available only for a maximum of 10 years (2001-2010), it was decided to compare the relevant weather variables from a 30-year dataset of baseline (1960-1990) weather data with the 30-year future climate data used for projections for the 15 locations in Anhui and Hubei provinces. For comparison of weather 
variables between the baseline climate (1960-1990) and 2020-2050 climate under the A1B scenario, 31 years of daily baseline climate data were obtained from PRECIS for each of the 15 locations. Weather variables were then calculated from these data to be representative of those that were identified as explanatory in the disease model. Since a straightforward comparison of weather variables was required, these variables were calculated with respect to an arbitrary anthesis date of 1 April for all locations; the same weather variables were then calculated from the 2020-2050 dataset.

\section{Validation of weather-based FEB model}

Validation was done to test if the relationship between FEB incidence and weather factors derived using observed weather data for the 10 locations was applicable to five other locations in Anhui province with wheat FEB and anthesis date data for 4 to 5 years but no weather stations nearby, using the weather data generated by PRECIS for the period 20012008. These data used for model validation were independent of data used for model construction. Weather variables were calculated from the simulated weather for the five locations to form the validation set, which comprised 36 sets of observations. Predicted values (expected values) for logit of the incidence of FEB were evaluated for the validation data set using the parameters estimated from the construction data set. To validate the model for predicting FEB, the mean squared error of prediction (MSEP) for the validation set (five locations) was compared to the same statistic calculated for the model construction data set (10 locations). Thus, for both data sets, the predicted FEB incidence was plotted against observed FEB incidence. The ratio of the two MSEPs was calculated and compared to the critical value from a table of the $F$ distribution. The model was assumed to be adequate for predicting FEB if the ratio was not statistically significant at $P<0.05$.

\section{Calibration and validation of wheat growth model Sirius anthesis date}

The wheat growth model Sirius was calibrated (adjustment of parameter values) and validated using observed data for wheat sowing date, anthesis date, maturity date and observed weather (including daily minimum temperature, maximum temperature, total rainfall and sunshine duration) to establish that this model can be applied to the projection of wheat anthesis date in China. Thus, data from experimental field trials including eight winter wheat cultivars with at least two successive years of data for sowing date, anthesis date and maturity date for each cultivar for the five locations (Tongcheng, Nanqiao, Lu'an, Fengtai 
and Fengyang) out of the 10 locations with observed disease data were used for the calibration and validation of Sirius anthesis date.

\section{Projection of wheat anthesis date for the period 2021-2050}

Wheat anthesis dates were projected for the period 2021-2050 (generation of anthesis date requires the weather data from the previous year, i.e. 2021 anthesis date requires 2020 weather data). Projected dates of wheat anthesis for the 15 locations for the period 2021-2050 were generated using the wheat growth model Sirius based on the projected climate data (daily minimum temperature, maximum temperature, total rainfall and solar radiation) from PRECIS and assuming a sowing date of 1 November for every location in every year (based on many observations of current sowing dates). Maps were produced by spatial interpolation between the 15 locations. To estimate the change in anthesis date, projected anthesis dates for 2021-2050 derived from the PRECIS climate projection were compared to the anthesis dates for 2001-2010.

\section{Projection of wheat FEB incidence for the period 2021-2050}

Using the climate data generated by PRECIS and the wheat anthesis dates data projected by Sirius, wheat FEB incidence projections were made based on the wheat FEB model for the 15 locations in Anhui and Hubei provinces in central China for the period 2021-2050. Maps were produced by spatial interpolation between the 15 locations. To estimate the change in FEB risk, projected FEB incidences for 2021-2050 under future climate projection were compared to the incidences for 2001-2010.

\section{Results}

\section{Relationships between incidence and severity (index) of FEB in central China}

Disease severity could not be used as the response variable because data were available for only two out of the 10 locations. The data for the other two possible response variables (disease incidence and disease index) were compared for all 10 locations and years (20012010). There was a good linear relationship between $\log _{10} F E B_{\text {index }}$ and $\log _{10} F E B_{\text {inci }}$ $\left(F E B_{\text {index }}\right.$ : disease index for $\mathrm{FEB} ; F E B_{\text {inci }}$ : \% ears affected by $\mathrm{FEB}$ ) for data from the 10 locations, which could be described by linear regression:

$\log _{10} F E B_{\text {index }}=0.96 \log _{10} F E B_{\text {inci }}-0.39$ 
The two variables accounted for $86.3 \%$ of the deviance where the standard errors were 0.033 for 0.96 and 0.026 for -0.39 . Since disease incidence was recorded for every location but disease index was not, It was decided to use disease incidence as the response variable for model construction. Disease incidence data were recorded regularly every 3 to 5 days between anthesis (April) and harvest (May, about 30 days after anthesis). Disease incidence was almost always greatest at the latest assessment date a few days before harvest. Therefore, the latest recorded disease incidence for each location and year was used as the measure of wheat FEB in that crop for modelling purposes (Figure 3).

(Figure 3 near here)

\section{Construction of weather-based model for FEB}

The incidence of FEB, measured as a percentage, was modelled by a linear combination of weather variables via the logit-link function in a generalized linear model with a binomial distribution. This is equivalent to logistic regression but with the response variable on a continuous scale between 0 and 100. This takes account of the way in which the variance is related to the expectation of the fitted proportion. The association with weather variables was investigated using maximum likelihood and step-wise selection of variables in GENSTAT. Weather variables were chosen for inclusion on the basis of the percentage of the deviance explained. The pair of weather variables with the best correlation with the response variable was:

Month1NR (the number of days of rainfall in the first month (a 30-day period) after anthesis date.)

WeekMinus3mT (maximum temperature for the period from 3 to 2 weeks before anthesis date.)

In combination, they accounted for $51.4 \%$ of the deviance and the corresponding coefficients (standard errors) were $0.24(0.030)$ and 0.12 (0.037), respectively. When single variables were tested, Month1NR and WeekMinus3mT accounted for $44.4 \%$ and $4.8 \%$ of the deviance, respectively. The model was therefore much improved by using both variables together (Eq. 1). 
$F E B_{\text {inoi }}=\frac{100 \exp (-7.25+0.12 \text { WeekMinus } 3 m T+0.24 \text { Month } 1 \mathrm{NR})}{1+\exp (-7.25+0.12 \text { WeekMinus } 3 m T+0.24 \text { Month } 1 \mathrm{NR})}$

\section{Validation of weather data generated by PRECIS}

Weather data were generated by PRECIS for 15 locations in Anhui and Hubei provinces, including the 10 locations used in model construction. Firstly, comparison was done between the PRECIS model output and the observed values for three weather variables (including daily mean temperature $\left({ }^{\circ} \mathrm{C}\right)$, daily maximum temperature $\left({ }^{\circ} \mathrm{C}\right)$ and number of days with $\geq$ 0.1mm rainfall in April and May of each year) out of the five weather variables selected for linear combination in GENSTAT from 2001 to 2008 for the 10 locations used in model construction. The results shown, by comparison with the 1:1 line, where the horizontal axis denotes the observed values and the vertical axis denotes the values generated by the PRECIS model (Supplementary Figure 2) for the daily mean temperature (a), daily maximum temperature (b) and number of days of rainfall (c), were all good.

Secondly, projected weather data for 2020-2050 were compared to the relevant weather variables from a 30-year dataset of baseline (1960-1990) weather data for the 15 locations in Anhui and Hubei provinces. From these data sets, the weather variables used in the model relative to an arbitrary anthesis date of 1 April were calculated, i.e. "mean maximum temperature from 3 to 2 weeks before anthesis (9-16 March)" and "number of days of rainfall $>=0.1 \mathrm{~mm}$ in April (30 days)". The total rainfall in April was also calculated and compared between the two data sets. When these variables were compared (Supplementary Figure 3), there was a $1-2{ }^{\circ} \mathrm{C}$ increase in the median (and mean; data not shown) temperature from the baseline to the 2020-2050 period, across all locations. There was also an increase in temperature variability for many locations, with temperature ranges wider in the projected than the baseline climate data. Number of days of rainfall in April did not change in any uniform manner across all locations. Total rainfall in April did increase across the locations, with the median for both the locations in Hubei province increasing by $c .100 \mathrm{~mm}$.

\section{Validation of weather-based wheat FEB model}


Validation of the FEB model was done using PRECIS model output for the period 2001-2008 after demonstrating that daily model output could be considered as equivalent to the observed weather data. Therefore, five locations in Anhui and Hubei provinces with good FEB data for 4 to 5 years but no weather stations nearby were selected for fusarium model validation using the daily output (daily maximum temperature and number of days of rainfall) from the PRECIS model. Thus, data used for model construction were independent of data used for model validation. To define whether or not the variation in the model validation data set was similar to the variation in the model construction data set, the mean squared errors of prediction for the two sets were calculated and the ratio was examined. This ratio is approximately an $F$ statistic with 70 and 36 degrees of freedom, respectively, from the numbers of observations in the two data sets. This was evaluated as a two-tailed test since there was no a priori reason to expect one mean squared error of prediction to be larger than the other. Thus, for the construction data set (10 locations) the predicted FEB incidence (derived from observed weather and anthesis date data) was plotted against observed FEB incidence. For the validation data set (five locations), the predicted FEB incidence (derived from PRECIS model output weather data and observed anthesis dates) was plotted against observed FEB incidence. The construction MSEP $=126.9 / 70=1.81$ and the validation MSEP $=100.8 / 36=2.8$. Using the larger MSEP as the numerator, $F=2.8 / 1.81=1.54$, with 36 and 70 degrees of freedom, $P=0.12$. Hence, the variation in the model validation set was not statistically significantly different from the variation in the model construction set (Figure 4).

(Figure 4 near here)

\section{Validation of wheat growth model Sirius anthesis date}

When the anthesis date data (days after sowing) predicted by the Sirius model for eight winter wheat cultivars (Yangmai 158, Yangmai 00126, Annong 95081-8, Fumai 9606, Yangmai No.11, Yangfumai 5242, Wanmai 606, Wanmai 202) for five locations in Anhui province (Tongcheng, Nanqiao, Lu'an, Fengtai and Fengyang) for at least two successive years during the period 2001-2010 were compared to the observed dates (Figure 5), the root mean squared deviation from the 1:1 line was 6.34 days.

(Figure 5 near here)

\section{Projection of wheat anthesis date for the period 2021-2050}


When projected dates of wheat anthesis for the period 2021-2050, obtained using Sirius, were compared to observed dates of anthesis for the period 2001-2010, the projected mean dates of anthesis were c. 3-6 days earlier for most of the 15 locations in Anhui and Hubei provinces (Figure 6), although there was little change at four locations. However, the projected advancement in anthesis date was greater for Jingzhou (24 March) and Jixi (22 March) in the south (7 days earlier than the earliest observed dates in 2001-2010) and Fengyang (4 April, 11 days earlier) and Tianchang (2 April, 13 days earlier) in the north of these two provinces.

(Figure 6 near here)

\section{Projection of wheat FEB incidence for the period 2021-2050}

The projected values for wheat FEB incidence were obtained by inserting projected anthesis dates and projected weather data into the FEB model (maximum temperature in the period from 3 to 2 weeks before anthesis and the number of days of rainfall in the 30-day period after anthesis). The mean FEB incidences projected for 2021-2050 ranged from 18\% (Fengtai) to 39\% (Jingzhou) (Figure 7; Supplementary Table 2). For each location, the projected incidences varied from year to year; at Fengtai from $4 \%$ to $42 \%$ and at Jingzhou from $7 \%$ to $76 \%$. The projected FEB incidences were generally smallest in the more northerly locations (Funan, Huoqiu, Fengtai, Changfeng, Fengyang in Anhui province) and greatest in the most southerly locations (Jingzhou and Qianjiang in Hubei province and Jixi in Anhui province).

(Figure 7 near here)

\section{Discussion}

This work suggests that climate change will increase the risk of serious FEB epidemics on winter wheat in central China by the middle of this century. Similar conclusions were reached about impacts of climate change on wheat FEB in the UK (Madgwick et al., 2011). However, the implications for food security in China are much more serious than those for the UK, since FEB is already a cause of substantial losses in wheat yield and quality in China (Parry et al., 1995; Qu et al., 2008; Ma et al., 2009). These losses are exacerbated by the production of mycotoxins by the Fusarium species associated with FEB in China and elsewhere (Franz et al., 2009; Schmidt-Heydt et al., 2011), which is predicted to increase under climate change (Chakraborty \& Newton, 2011). Since wheat is an essential staple crop over large areas of China, these predicted impacts of climate change provide a guide to Chinese government and 
industry preparation for adaptation to climate change. Since other weather-based models to predict risk of FEB developed for Argentina, the USA, Italy, Brazil and the UK (Moschini et al., 2001; De Wolf et al., 2003; Rossi et al., 2003; Del Ponte et al., 2005; Madgwick et al., 2011) are country-specific, it is important to use them to develop country-specific projections of impacts of climate change. To guide government and industry planning for adaptation to climate change, it is also essential to estimate impacts of climate change on other important crop diseases, for example phoma stem canker of oilseed rape (Evans et al., 2008).

However, to obtain accurate estimates of direct impacts of climate change on crop diseases, it is necessary to incorporate impacts of climate change on the crop, in this instance the date of anthesis, since FEB develops on wheat only if it is infected by Fusarium during anthesis (Parry et al., 1995; Goswami \& Kistler, 2004; Xu et al., 2007; West et al., 2012). To do this, it is necessary to combine crop growth models with weather-based disease models (Butterworth et al., 2010; Madgwick et al., 2011). However, the weather-based model accounted for only half the deviance in incidence of FEB in central China, as in the UK (Madgwick et al., 2011), because factors other than weather affect epidemic development. For FEB, an important factor is the proximity of previous maize crops, since maize debris is a potent source of inoculum of F. graminearum (Chakraborty \& Newton, 2011; West et al., 2012). Thus there may be indirect impacts of climate change on the severity of FEB epidemics, as farmers change agronomic practices as part of strategies for adaptation to climate change (Barnes et al., 2010). For example, in the UK there may be more maize grown since it is a crop that it well adapted to the higher temperatures that are projected for the UK (West et al., 2012). Farmers may also manipulate wheat anthesis date, for example by using cultivars that mature more or less rapidly or by changing sowing date.

The observation that the weather variables with the best correlation to the incidence of FEB in China were rainfall and temperature is consistent with models developed for other countries (Moschini et al., 2001; De Wolf et al., 2003; Rossi et al., 2003; Del Ponte et al., 2005; Madgwick et al., 2011). The correlation with temperature from 3 to 2 weeks before anthesis (cf. the correlation of FEB incidence with temperature in the period 6 to 2 weeks before anthesis in the UK, Madgwick et al., 2011) may relate to influence of increased temperature on Fusarium growth and sporulation (Doohan et al., 2003). The relationship with rainfall after anthesis could be due to the effect of rain on infection and subsequent growth of Fusarium within the wheat (Xu et al., 2007). 
Strategies to decrease the future threat from FEB should be a major priority for Chinese government and industry, as part of strategies for adaptation to climate change. There is a need to breed new wheat cultivars with effective resistance against the Fusarium species that cause FEB (Xu \& Nicholson, 2009); this resistance must be able to operate at the increased temperatures that are expected, since some crop resistance becomes ineffective at increased temperature (Huang et al., 2006). Fungicide treatment to control the disease should also be considered (Xu \& Nicholson, 2009), providing it is economically feasible to do so in China. Nevertheless, since either breeding a new source of resistance into a cultivar or development of a new fungicide can take 10-15 years, it is important to start adaptation to impacts of climate change on crop diseases now (Barnes et al., 2010). Such strategies for adaptation to impacts of climate change on FEB will contribute to sustainable wheat production and improved food security (Beddington, 2010).

\section{Acknowledgements}

We thank the SAIN (Sustainable Agriculture Innovation Network; www.sainonline.org/English.html) project (No. DC09-07), the UK Department for Environment Food and Rural Affairs (Defra), the UK Biotechnology and Biological Sciences Research Council (BBSRC; Centre for Bioenergy and Climate Change ISPG) and the Chinese Ministry of Agriculture for funding this research. JH is funded through the Grantham Institute for Climate Change, Imperial College. We are grateful to Sheng-Yi Liu at the Chinese Academy of Agricultural Sciences, Mat Fisher at Imperial College, Yong-Ju Huang at the University of Hertfordshire, Pierre Stratonovitch at Rothamsted Research, Tim Wheeler at Reading University and Richard Jones at the UK Met Office for advice and to staff of the Hubei and Anhui Plant Protection Stations for collecting data.

\section{References}

Anonymous. (2009) 1.02 billion people hungry; one sixth of humanity undernourished - more than ever before. FAO (Food and Agriculture Organisation of the United Nations). [http://www.fao.org/news/story/en/item/20568/icode/]

Barnes A.P., Wreford A., Butterworth M.H., Semenov M.A., Moran D., Evans N., Fitt B.D.L. (2010) Adaptation to increasing severity of phoma stem canker on winter oilseed rape in the UK under climate change. Journal of Agricultural Science, 148, 683-694. 
Beddington J. (2010) Food security: contributions from science to a new and greener revolution. Philosophical Transactions of the Royal Society B: Biological Sciences, 365, $61-71$.

Butterworth M.H., Semenov M.A., Barnes A., Moran D., West J.S., Fitt B.D.L. (2010) North-South divide: contrasting impacts of climate change on crop yields in Scotland and England. Journal of Royal Society Interface, 7, 123-130.

Chakraborty S., Newton A.C. (2011) Climate change, plant diseases and food security: an overview. Plant Pathology, 60, 2-14.

Chakraborty S., Tiedemann A.V., Teng P.S. (2000) Climate change: potential impact on plant diseases. Environmental Pollution, 108, 317-326.

Christensen J.H., Hewitson B., Busuioc A., Chen A., Gao X., Held I., Jones R., Kolli R.K., Kwon W.T., Laprise R., et al. (2007) Regional Climate Projections. In Climate Change 2007: The Physical Science Basis. Contribution of Working Group I to the Fourth Assessment Report of the Intergovernmental Panel on Climate Change. (eds Solomon S, Qin D, Manning M, Chen Z, Marquis M, Averyt KB, Tignor M and Miller HL) Cambridge, UK and New York, NY, USA: Cambridge University Press.

De Wolf E.D., Madden L.V., Lipps P.E. (2003) Risk assessment models for wheat fusarium head blight epidemics based on within-season weather data. Phytopathology, 93, 428-435.

Dee D.P., Uppala S.M., Simmons A.J., Berrisford P., Poli P., Kobayashi S., Andrae U., Balmaseda M.A., Balsamo G., Bauer P., et al. (2011) The ERA-Interim reanalysis: configuration and performance of the data assimilation system. Quarterly Journal of the Royal Meteorological Society, 137, 553-597.

Del Ponte E.M.D., Fernandes J.M.C., Pavan W. (2005) A risk infection simulation model for fusarium head blight of wheat. Fitopatologia Brasileira, 30, 634-642.

Doohan F., Brennan J.M., Cooke B.M. (2003) Influence of climatic factors on Fusarium species pathogenic to cereals. European Journal of Plant Pathology, 109, 755-768. 
Evans N., Baierl A., Semenov M.A., Gladders P., Fitt B.D.L. (2008) Range and severity of a plant disease increased by global warming. Journal of Royal Society Interface, 5, 525-531.

Franz E., Booij K., van der Fels-Klerx I. (2009) Prediction of deoxynivalenol content in Dutch winter wheat. Journal of Food Protection, 72, 2170-2177.

Gordon C., Cooper C., Senior C., Banks H., Gregory J.M., Johns T.C., Mitchell J.F.B., Wood R.A. (2000) The simulation of SST, sea ice extents and ocean heat transports in a version of the Hadley Centre coupled model without flux adjustments. Climate Dynamics, 16, 147-168.

Goswami R.S., Kistler H.C. (2004) Heading for disaster: Fusarium graminearum on cereal crops. Molecular Plant Pathology, 5, 515-525.

Huang Y.J., Evans N., Li Z.Q., Eckert M., Chevre A.M., Renard M., Fitt B.D.L. (2006) Temperature and leaf wetness duration affect phenotypic expression of Rlm6-mediated resistance to Leptosphaeria maculans in Brassica napus. New Phytologist, 170, 129-141.

Jamieson P., Semenov M.A., Brooking I., Francis G. (1998) Sirius: a mechanistic model of wheat response to environmental variation. European Journal of Agronomy, 8, 161-179.

Jones R., Noguer M., Hassell D.C., Hudson D., Wilson S.S., Jenkins G.J., Mitchell J.F.B. (2004) Generating high resolution climate change scenarios using PRECIS. Met Office Hadley Centre, Exeter, UK, 40pp.

Lancashire P.D., Bleiholder H., Boom T.V.D., Langelüddeke P., Stauss R., Weber E., Witzenberger A. (1991) A uniform decimal code for growth stages of crops and weeds. Annals of Applied Biology, 119, 561-601.

Ma H.X., Ge H., Zhang X., Lu W., Yu D., Chen H., Chen J. (2009) Resistance to fusarium head blight and deoxynivalenol accumulation in Chinese barley. Journal of Phytopathology. 157, 166-171.

Madgwick J.W., West J.S., White R.P., Semenov M.A., Townsend J.A., Turner J.A., Fitt B.D.L. (2011) Impacts of climate change on wheat anthesis and fusarium ear blight in the UK. European Journal of Plant Pathology, 129, 117-131. 
Mahmuti M., West J.S, Watts J., Gladders P., Fitt B.D.L. (2009) Controlling crop disease contributes to both food security and climate change mitigation. International Journal of Agricultural Sustainability, 7, 189-202.

Moschini R.C., Pioli R., Carmona M., Sacchi O. (2001) Empirical predictions of wheat head blight in the northern Argentinean Pampas region. Crop Science, 41, 1541-1545.

Nakicenovic N., Alcamo J., Davis G., Vries B., de Fenhann J., Gaffin S., Gregor K., Grübler A., Jung T.Y., Kram T., et al. (2000) Emissions Scenarios. In Special Report of the Intergovernmental Panel on Climate Change. (eds Nakicenovic N \& Swart R). Cambridge University Press, Cambridge.

Parry D.W., Jenkinson P., McLeod L. (1995) Fusarium ear blight (scab) in small grain cereals - a review. Plant Pathology, 44, 207-238.

Paul P.A., Lipps P.E., De Wolf E., Shaner G., Buechley G., Adhikari T., Ali S., Stein J., Osborne L., Madden L.V. (2007) A distributed lag analysis of the relationship between Gibberella zeae inoculum density on wheat spikes and weather variables. Phytopathology, 97, 1608-1624.

Payne R.W., Harding S.A., Murray D.A., Soutar D.M., Baird D.B., Glaser A.I., Welham S.J., Gilmour A.R., Thompson R., Webster R. (2011) The Guide to GenStat Release 14, Part 2: Statistics. VSN International Ltd, Hemel Hempstead, UK.

Qu B., Li H.P., Zhang J.B., Xu Y.B., Huang T., Wu A.B., Zhao C.S., Carter J.P., Nicholson P., Liao Y.C. (2008) Geographic distribution and genetic diversity of Fusarium graminearum and F. asiaticum on wheat spikes throughout China. Plant Pathology, 57, $15-24$.

Rossi V., Giosuè S., Pattori E., Spanna F., Del Vecchio A. (2003) A model estimating the risk of fusarium head blight on wheat. EPPO Bulletin, 33, 421-425.

Roudier P., Sultan B., Quirion P., Berg A. (2011) The impact of future climate change on West African crop yields: What does the recent literature say? Global Environmental Change. 21, 1073-1083. 
Schmidt-Heydt M., Parra R., Geisen R., Magan N. (2011) Modelling the relationship between environmental factors, transcriptional genes and deoxynivalenol mycotoxin production by strains of two Fusarium species. Journal of Royal Society Interface, 8, 117-126.

Stratonovitch P., Storkey J., Semenov M.A. (2012) A process-based approach to modelling impacts of climate change on the damage niche of an agricultural weed. Global Change. Biology, 18, 2071-2080.

West J.S., Holdgate S., Townsend J.A., Edwards S.G., Jennings P., Fitt B.D.L. (2012) Impacts of changing climate and agronomic factors on fusarium ear blight of wheat in the UK. Fungal Ecology, 5, 53-61.

Xu X.M., Monger W., Ritieni A., Nicholson P. (2007) Effect of temperature and duration of wetness during initial infection periods on disease development, fungal biomass and mycotoxin concentrations on wheat inoculated with single, or combinations of, Fusarium species. Plant Pathology, 56, 943-956.

Xu X.M., Nicholson P. (2009) Community ecology of fungal pathogens causing wheat head blight. Annual Review of Phytopathology, 47, 83-103. 


\section{Supporting information}
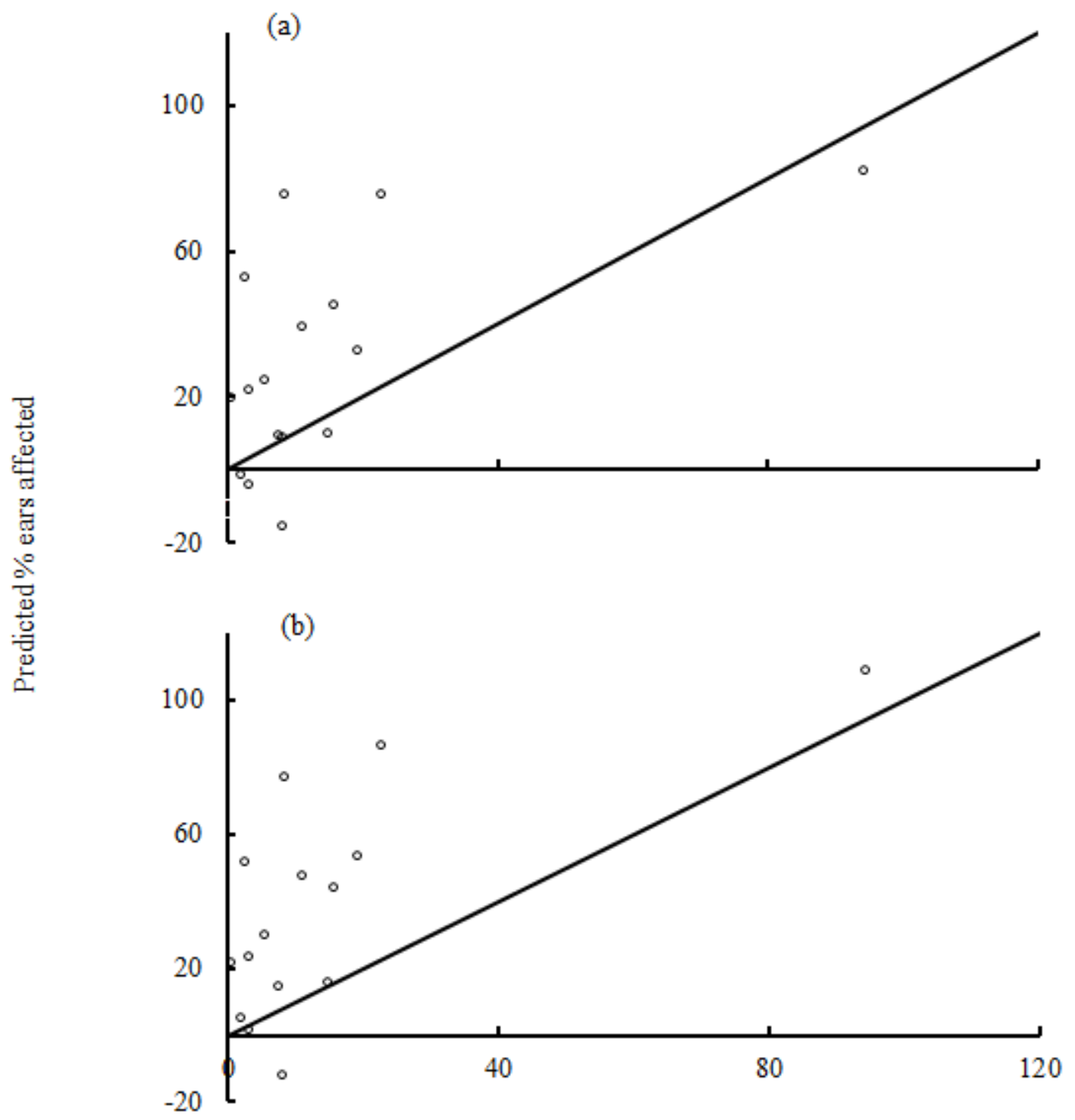

Observed \% ears affected

Supplementary Figure 1 Two Argentinian models were tested using observed Chinese weather data and fusarium ear blight data. These model equations are:

$$
\begin{aligned}
& \mathrm{PI}=20.37+8.63 N P_{2}-0.49 D D_{926} \\
& \mathrm{PI}=18.34+4.12 N P_{12}-0.45 D D_{1026}
\end{aligned}
$$

In these two models (Moschini et al., 2001), fusarium ear blight incidence (\% ears affected) is PI. $N P_{2}$ is number of 2 -day periods with precipitation $(\geq 0.2 \mathrm{~mm})$ and relative humidity $>81 \%$ on the first day and relative humidity $\geq 78 \%$ on the second day; $N P_{12}$ is total 
number of $N P_{2}$ periods plus total number of days in which both precipitation $\geq 0.2 \mathrm{~mm}$ and mean relative humidity $>83 \%$. The two variables $D D_{926}$ and $D D_{1026}$ are calculated as:

$$
\begin{aligned}
& \left.D D_{926}=\Sigma[(\operatorname{MaxT})-26)+(9-\operatorname{MinT})\right] \\
& D D_{1026}=\Sigma[(\operatorname{MaxT}-26)+(10-\operatorname{MinT})]
\end{aligned}
$$

where MaxT denotes the daily maximum temperature (summed for those days when MaxT was greater than $26^{\circ} \mathrm{C}$ ), MinT is the daily minimum temperature (summed for those days when MinT was less than $\left.9^{\circ} \mathrm{C}\left(10^{\circ} \mathrm{C}\right)\right)$. When observed Chinese weather data were substituted into the two Argentinian models, most of the predicted values of incidence were much greater than the observed values for both model [1] (panel (a)) and model [2] (panel (b)). 


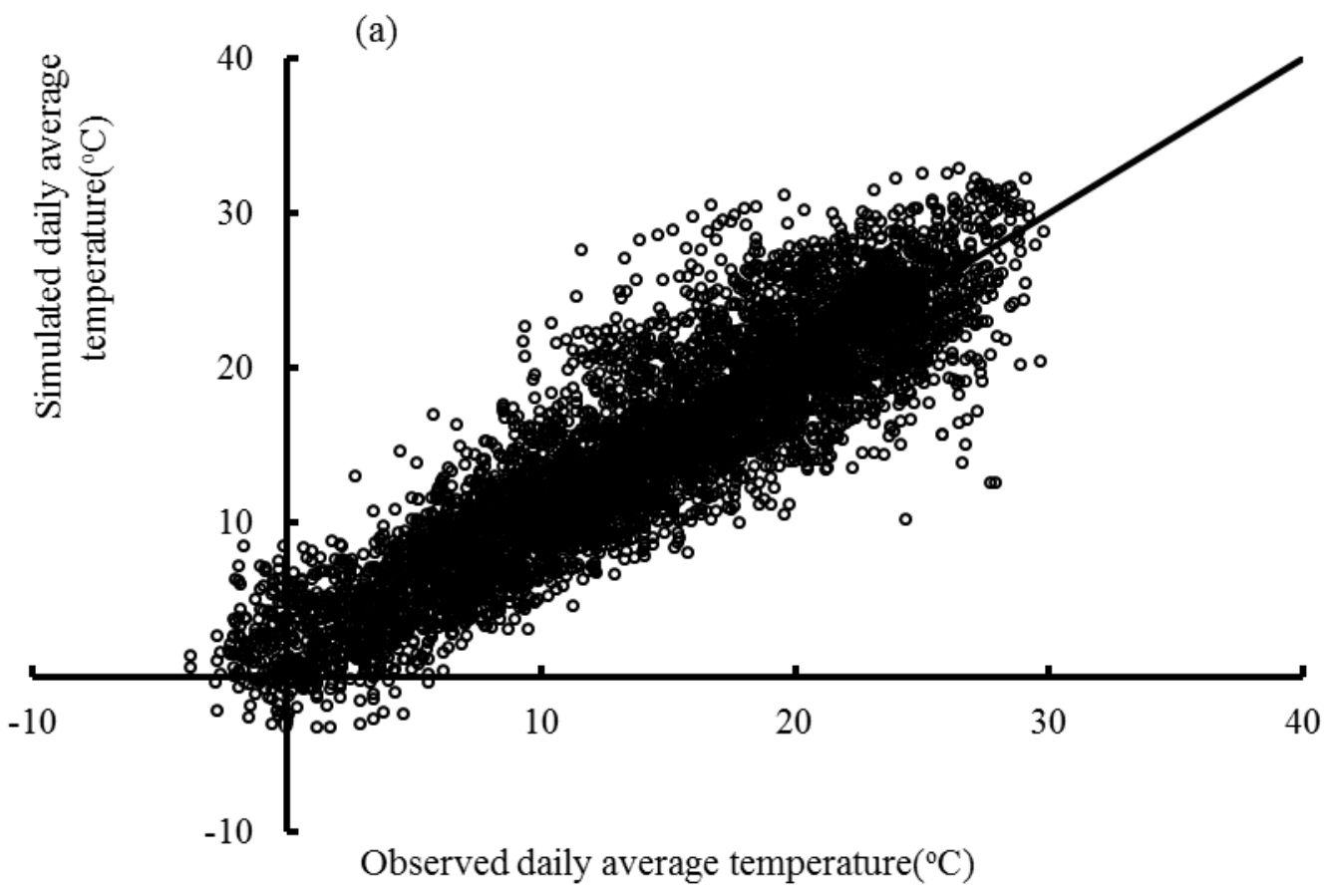

(b)

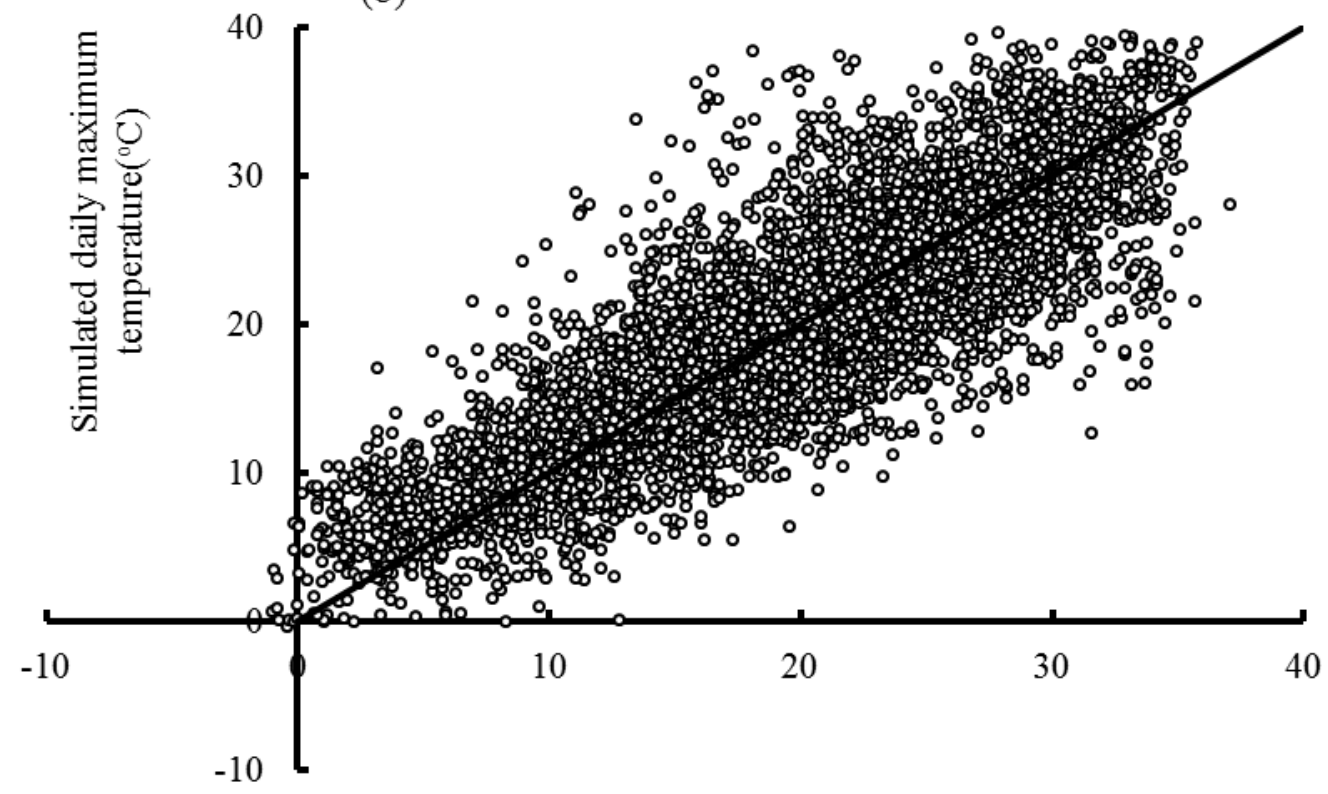

Observed daily maximum temperature $\left({ }^{\circ} \mathrm{C}\right)$ 


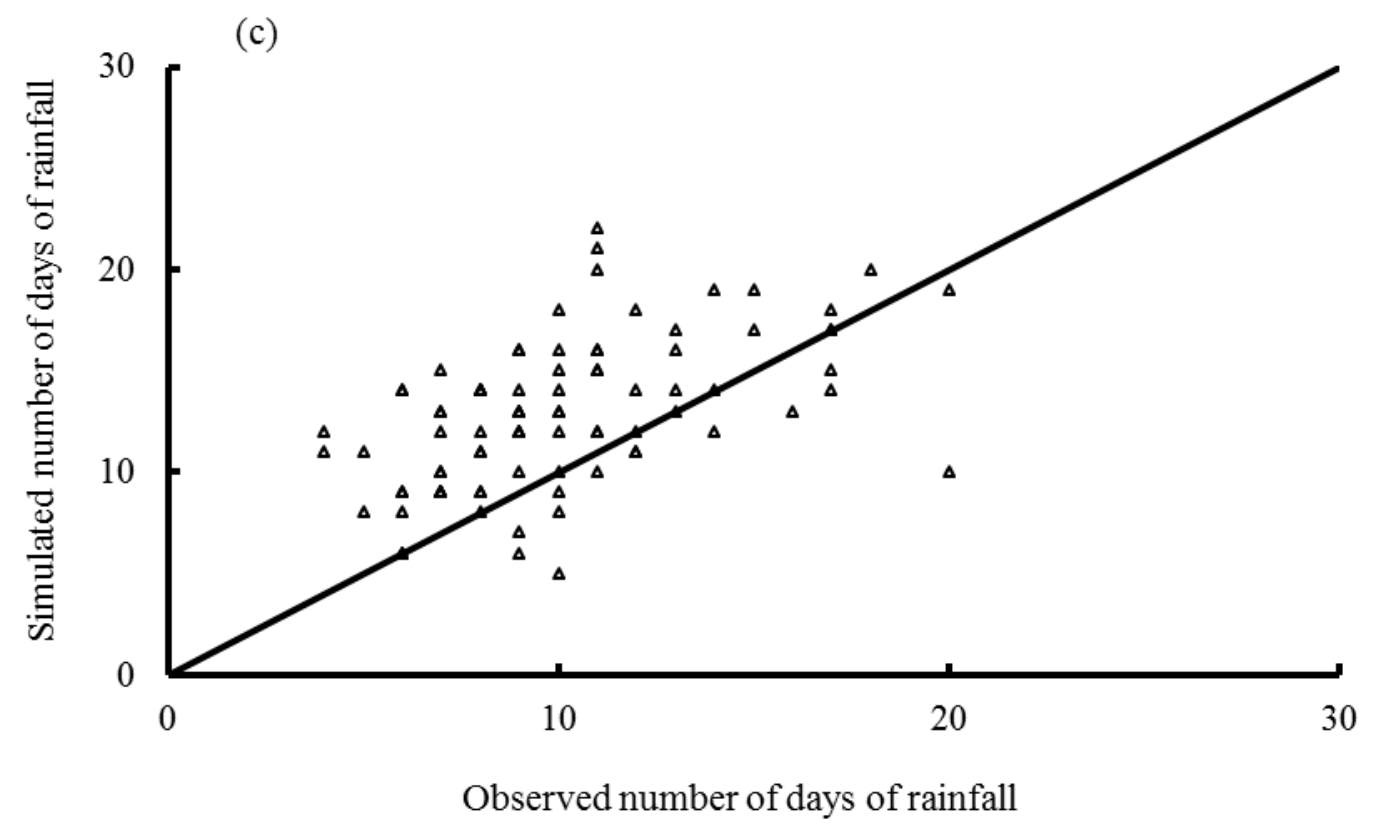

Supplementary Figure 2 Validation of weather data generated by PRECIS. Weather data for years 2001-2008 (including (a) daily mean temperature $\left({ }^{\circ} \mathrm{C}\right), \quad(b)$ daily maximum temperature $\left({ }^{\circ} \mathrm{C}\right)$ and $(\mathrm{c})$ number of days with $\geq 0.1 \mathrm{~mm}$ rainfall in April and May for each year) generated by the PRECIS model were compared with the observed weather data for the 10 locations in Anhui and Hubei provinces in central China that were used in model construction. The root mean squared values of deviation from the 1:1 lines for the variables were: $3.38^{\circ} \mathrm{C}(\mathrm{a}), 4.53^{\circ} \mathrm{C}(\mathrm{b})$ and 4.42 days (c). 

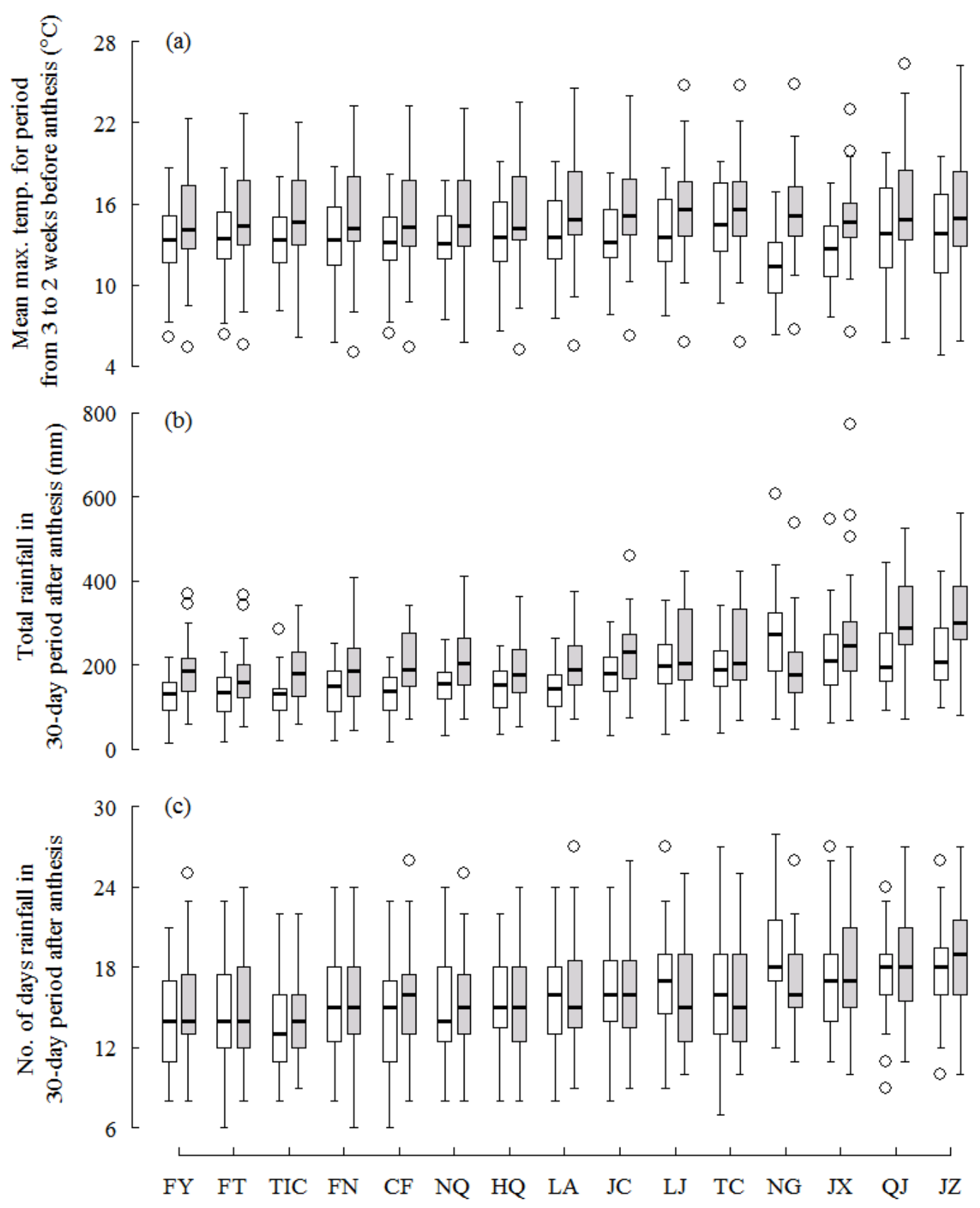

Supplementary Figure 3 Comparison of weather variables between baseline climate data and climate scenario A1B data. Weather variables were compared between 30 years of baseline climate data (model output for 1960-1990 ' $\square$ ') and 30 years of projected data for climate change scenario A1B (model output 2020-2050 ‘ $\square$ ') for the 15 locations in Anhui and Hubei provinces. For each location and weather variable, the 30 years of data are represented by a box plot. For all plots: 1 . The bold line within the box indicates the median value (50th percentile); 2 . The lower and upper edges of the box represent the 1 st and 3 rd quartiles respectively (25th and 75th percentiles); 3 . The whiskers extend above the third 
quartile or below the first quartile to the range of the data or to $1.5 \times$ (inter-quartile range) if there are values which lie outside these limits (these are outliers, shown as circles (o) beyond the whisker ends). Weather variables were chosen to represent those in the fusarium ear blight model with anthesis date assumed to be 1 April. Mean values of maximum temperature for the period from 3 to 2 weeks before anthesis date (a) were $1-2^{\circ} \mathrm{C}$ greater for the 2020-2050 period than the baseline period for all locations. The number of days of rainfall in the 30 days after anthesis date (b) did not show a clear change for each location from the baseline period to the 2020-2050 period. The total rainfall in April (c) was greater in the 2020-2050 period than in the baseline period (1960-1990) for most locations. For details of locations, see supplementary Table 1. 
Supplementary Table 1 Location information and data available for 15 locations in Anhui and Hubei provinces in central China. These locations have wheat fusarium ear blight data (1-6 cultivars depending on location and year) from commercial winter wheat crops. These locations were selected for generation of weather data for 2001-2008 and projected climate data for the climate change scenario A1B for the period 2020-2050. Latitude, longitude and altitude data for each location were obtained from http://www.hjqing.com/find/jingwei/. The observed wheat anthesis dates for these cultivars were available for each location and observed weather data (within 5, 20 or $30 \mathrm{~km}$ ) were available for 10 out of the 15 locations.

\begin{tabular}{|c|c|c|c|c|c|c|c|}
\hline Location & Province & $\begin{array}{l}\text { Latitude } \\
\text { (degrees) }\end{array}$ & $\begin{array}{l}\text { Longitude } \\
\text { (degrees) }\end{array}$ & $\begin{array}{l}\text { Altitude } \\
\text { (m above } \\
\text { sea level) }\end{array}$ & $\begin{array}{l}\text { Fusarium } \\
\text { ear blight } \\
\text { data (no. } \\
\text { cultivars) }\end{array}$ & $\begin{array}{c}\text { Observed } \\
\text { weather } \\
\text { data } \\
\text { (within x } \\
\text { km) }\end{array}$ & $\begin{array}{l}\text { Anthesis } \\
\text { date } \\
\text { data (no. } \\
\text { cultivars) }\end{array}$ \\
\hline $\begin{array}{c}\text { Jingzhou } \\
\text { (JZ) }\end{array}$ & Hubei & 30.3 & 112.1 & 34 & $2-5$ & 5 & $2-5$ \\
\hline $\begin{array}{c}\text { Qianjiang } \\
\text { (QJ) }\end{array}$ & Hubei & 30.4 & 112.8 & 32 & $2-6$ & 30 & $2-6$ \\
\hline $\begin{array}{c}\text { Fengyang } \\
\text { (FY) }\end{array}$ & Anhui & 32.9 & 117.4 & 57 & $2-3$ & 20 & $2-3$ \\
\hline $\begin{array}{l}\text { Lu'an } \\
\text { (LA) }\end{array}$ & Anhui & 31.7 & 116.5 & 58 & $2-3$ & 5 & $2-3$ \\
\hline $\begin{array}{c}\text { Ningguo } \\
\text { (NG) }\end{array}$ & Anhui & 30.6 & 119.0 & 59 & 1 & 5 & 1 \\
\hline Juchao (JC) & Anhui & 31.6 & 117.9 & 18 & $1-2$ & 5 & $1-2$ \\
\hline $\begin{array}{l}\text { Fengtai } \\
\text { (FT) }\end{array}$ & Anhui & 32.7 & 116.7 & 22 & $2-3$ & 20 & $2-3$ \\
\hline $\begin{array}{l}\text { Tongcheng } \\
\text { (TC) }\end{array}$ & Anhui & 31.1 & 117.0 & 45 & 1 & 5 & 1 \\
\hline Funan (FN) & Anhui & 32.6 & 115.6 & 30 & $2-3$ & 30 & $2-3$ \\
\hline $\begin{array}{c}\text { Nanqiao } \\
\text { (NQ) }\end{array}$ & Anhui & 32.3 & 118.3 & 15 & 2 & 5 & 2 \\
\hline Huoqiu & Anhui & 32.3 & 116.3 & 24 & $2-3$ & ${ }_{-}^{b}$ & $2-3$ \\
\hline
\end{tabular}




\section{Fusarium and climate change in China}

\begin{tabular}{|c|c|c|c|c|c|c|c|}
\hline (HQ) & & & & & & & \\
\hline $\begin{array}{l}\text { Jixi } \\
(J X)\end{array}$ & Anhui & 30.1 & 118.6 & 187 & 1 & $-{ }^{b}$ & 1 \\
\hline $\begin{array}{c}\text { Changfeng } \\
\text { (CF) }\end{array}$ & Anhui & 32.5 & 117.2 & 28 & $1-2$ & $-{ }^{b}$ & $1-2$ \\
\hline Lujiang (LJ) & Anhui & 31.2 & 117.2 & 34 & 2 & $-{ }^{b}$ & 2 \\
\hline $\begin{array}{c}\text { Tianchang } \\
\text { (TIC) }\end{array}$ & Anhui & 32.7 & 119.0 & 12 & $2-3$ & $-^{b}$ & $2-3$ \\
\hline
\end{tabular}

${ }^{\mathrm{a}}$ The number of cultivars varied from year to year.

${ }^{b}$ No nearby weather stations to provide observed weather data. 
Supplementary Table 2 Projected fusarium ear blight incidence (\% ears affected). Projected mean fusarium ear blight incidence for period 2021-2050 for the 15 locations in Anhui and Hubei provinces was compared with the observed mean fusarium ear blight incidence for between 3 and 10 years per location from 2001 to 2010. The projected (2021-2050) mean fusarium ear blight incidence was greater than the observed (2001-2010) incidence.

Mean fusarium ear blight incidence (\% ears affected)

\begin{tabular}{ccc}
\hline Location & $\begin{array}{c}\text { Observed } \\
(2001-2010)\end{array}$ & $\begin{array}{c}\text { Projected } \\
(2021-2050)\end{array}$ \\
\hline Jingzhou (JZ) & 14.0 & 39.0 \\
Qianjiang (QJ) & 14.2 & 36.2 \\
Fengyang (FY) & 5.5 & 20.2 \\
Lu'an (LA) & 17.3 & 27.4 \\
Ningguo (NG) & 5.0 & 30.5 \\
Juchao (JC) & 15.7 & 27.9 \\
Fengtai (FT) & 6.0 & 18.2 \\
Tongcheng (TC) & 0.8 & 28.2 \\
Funan (FN) & 2.2 & 18.9 \\
Nanqiao (NQ) & 7.8 & 23.9 \\
Huoqiu (HQ) & 4.8 & 21.4 \\
Jixi (JX) & 9.7 & 37.2 \\
Changfeng (CF) & 3.6 & 23.5 \\
Lujiang (LJ) & 20.3 & 28.2 \\
Tianchang (TIC) & 5.2 & 19.7 \\
\hline
\end{tabular}




\section{Figure legends}

Figure 1 Distribution of wheat cropping in China in relation to regions with serious fusarium ear blight epidemics. Arable land on the Chinese mainland where there is widespread cultivation of wheat (winter wheat shown by the red dots, spring wheat shown by the blue lines and grey means both) and regions where serious epidemics of fusarium ear blight occur (within black line including the region in central China and a small region in the northeast). In the region in central China, the green dots denote the 10 locations with observed disease, anthesis date and weather data that were used for fusarium model construction and the black dots denote the five locations with disease and anthesis date data but no weather data that were used for model validation using the weather data generated by PRECIS. (Map adapted from national agricultural atlas of the People's Republic of China and http://www.nal.usda.gov/pgdic/WHS/intro.html )

Figure 2 Stages in modelling wheat fusarium ear blight (FEB) and producing projections of incidence under climate change in central China. 1. Observed data for fusarium ear blight incidence (\% ears affected), anthesis date and weather (daily temperature $\left({ }^{\circ} \mathrm{C}\right)$, total rainfall $(\mathrm{mm})$, relative humidity (\%) and sunshine duration (hours)) were collated from a number of sources for at least 10 locations in Anhui and Hubei provinces for the years 2001-2010. 2. A model was constructed from data for fusarium ear blight incidence from 10 locations with observed disease, anthesis date and weather data; the model related fusarium ear blight incidence to maximum temperature for the period from 3 to 2 weeks before anthesis date and the number of days with $\geq 0.1 \mathrm{~mm}$ rainfall in a 30-day period after anthesis. 3 . Weather data for 2001-2008 were generated using PRECIS for another five locations in Anhui province with disease and anthesis date data but no weather data. 4. FEB model was validated by comparing the mean squared errors of prediction for the model construction data set with those for the independent validation data set for the period 2001-2008. 5. The dates of anthesis predicted using the wheat growth model Sirius for eight winter wheat cultivars were validated by comparing predicted anthesis dates with observed anthesis dates for each cultivar for five locations in Anhui province (Tongcheng, Nanqiao, Lu'an, Fengtai and Fengyang) for the period 2001-2010. 6. Climate data were generated using PRECIS for all 15 locations for climate change scenario A1B for the period 2020-2050. 7. The dates of anthesis were projected for each location for climate change scenario A1B using 
Sirius and the climate data generated by PRECIS. 8. Using the climate data generated by PRECIS and mean date of anthesis projected using Sirius for each of the locations for the climate change scenario $\mathrm{A} 1 \mathrm{~B}$, the model was used to project fusarium ear blight incidence for the 15 locations for the climate change scenario A1B for the period 2021-2050 (the model requires data from the previous year, e.g. 2021 needs data for 2020).

Figure 3 Relationship between fusarium ear blight incidence (\% ears affected, $F E B_{\text {inci }}$ ) and index $\left(F E B_{\text {index }}\right)$. Disease data (including incidence $F E B_{\text {inci }}$ and index $F E B_{\text {index }}$, calculated from disease severity: $100 \Sigma\left(i n_{i}\right) /\left(\max \{i\} \Sigma n_{i}\right), i=1,2,3,4,5$, where $i$ is the value of fusarium ear blight severity, $n_{i}$ is the number of the ears with severity i) for the 10 locations used in model construction were collated. Since disease data were recorded regularly every 3 to 5 days in the 30-day period between anthesis (April) and harvest (May) for the 10 locations in every year, there were more than 100 pairs of values. For the 10 locations in Anhui and Hubei provinces from 2001 to 2010, there was a good linear relationship between $\log _{10} F E B_{\text {inci }}$ and $\log _{10} F E B_{\text {index }}$ that satisfied the equation:

$\log _{10} F E B_{\text {index }}=0.96 \log _{10} F E B_{\text {inci }}-0.39$,

The two variables accounted for $86.3 \%$ of the deviance where the standard errors were 0.033 for 0.96 and 0.026 for -0.39 .

Figure 4 Validation of weather-based wheat fusarium ear blight incidence (\% ears affected) model. To define whether or not the variation in the model validation data set $(\boldsymbol{\Delta})$ was similar to the variation in the model construction data set (o), the mean squared errors of prediction for the two sets were calculated and the ratio between them was examined. This ratio is approximately an $F$ statistic with 70 and 36 degrees of freedom, respectively, from the numbers of observations in each data set. This was evaluated as a two-tailed test since there was no a priori reason to expect one mean squared error of prediction to be larger than the other. Thus, for the construction data set (10 locations), the predicted fusarium ear blight incidence (derived from observed weather data and anthesis data) was plotted against observed incidence. For the validation data set (five locations), the predicted incidence (derived from weather data from PRECIS model output and observed anthesis date) was plotted against observed incidence. The construction MSEP $=126.9 / 70=1.81$, 
and validation MSEP $=100.8 / 36=2.8$. Using the larger MSEP as the numerator, $F=2.8 / 1.81$ $=1.54$, with 36 and 70 degrees of freedom, $P=0.12$. Hence, the variation in the model validation set was not statistically significantly different from the variation in the model construction set.

Figure 5 Validation of winter wheat growth model Sirius date of anthesis (growth stage 65). The inputs to the Sirius model included observed weather (daily minimum temperature $\left({ }^{\circ} \mathrm{C}\right.$ ), maximum temperature $\left({ }^{\circ} \mathrm{C}\right)$, total rainfall $(\mathrm{mm})$ and sunshine duration (hours)) and wheat sowing dates for the eight winter wheat cultivars (Yangmai $158(\diamond)$, Yangmai $00126(\Delta)$, Annong 95081-8 (॰), Fumai 9606 (•), Yangmai No.11 (১), Yangfumai 5242 (॰), Wanmai 606 (ム), Wanmai 202 (.)) planted as lines in the experimental field trials at five locations (Tongcheng, Nanqiao, Lu'an, Fengtai and Fengyang) in Anhui province for at least two successive years during the period 2001-2010. The anthesis dates from Sirius for the eight cultivars for at least two years during the period 2001-2010 were recorded as days after sowing. Thus, validation of wheat anthesis dates predicted by the Sirius model for the eight cultivars was done by comparing predicted to observed anthesis dates. The root mean squared value of deviation from the $1: 1$ line was 6.34 days.

Figure 6 Projected wheat anthesis dates. Comparison between observed mean dates of anthesis (1-6 cultivars) for the 15 locations in Anhui and Hubei provinces for between 3 and 10 years per location from 2001 to 2010 (a) and projected mean dates of anthesis for 20212050 (b) generated by the wheat growth model Sirius for each of the 15 locations under climate scenario A1B using the projected climate data from PRECIS (2020-2050). The maps were produced by spatial interpolation between the 15 locations. For details of locations, see Supplementary Table 1.

Figure 7 Projected fusarium ear blight incidence (\% ears affected). Comparison between the observed mean fusarium ear blight incidence (for 1-6 cultivars) for the 15 locations in Anhui and Hubei provinces for between 3 and 10 years per location from 2001 to 2010 (a) and the projected mean fusarium ear blight incidence for 2021-2050 (b) generated by the fusarium model under climate scenario A1B using the mean anthesis dates generated by Sirius for each of the 15 locations. The maps were produced by spatial interpolation between the 15 locations. For details of locations, see Supplementary Table 1. 


\section{Figures}

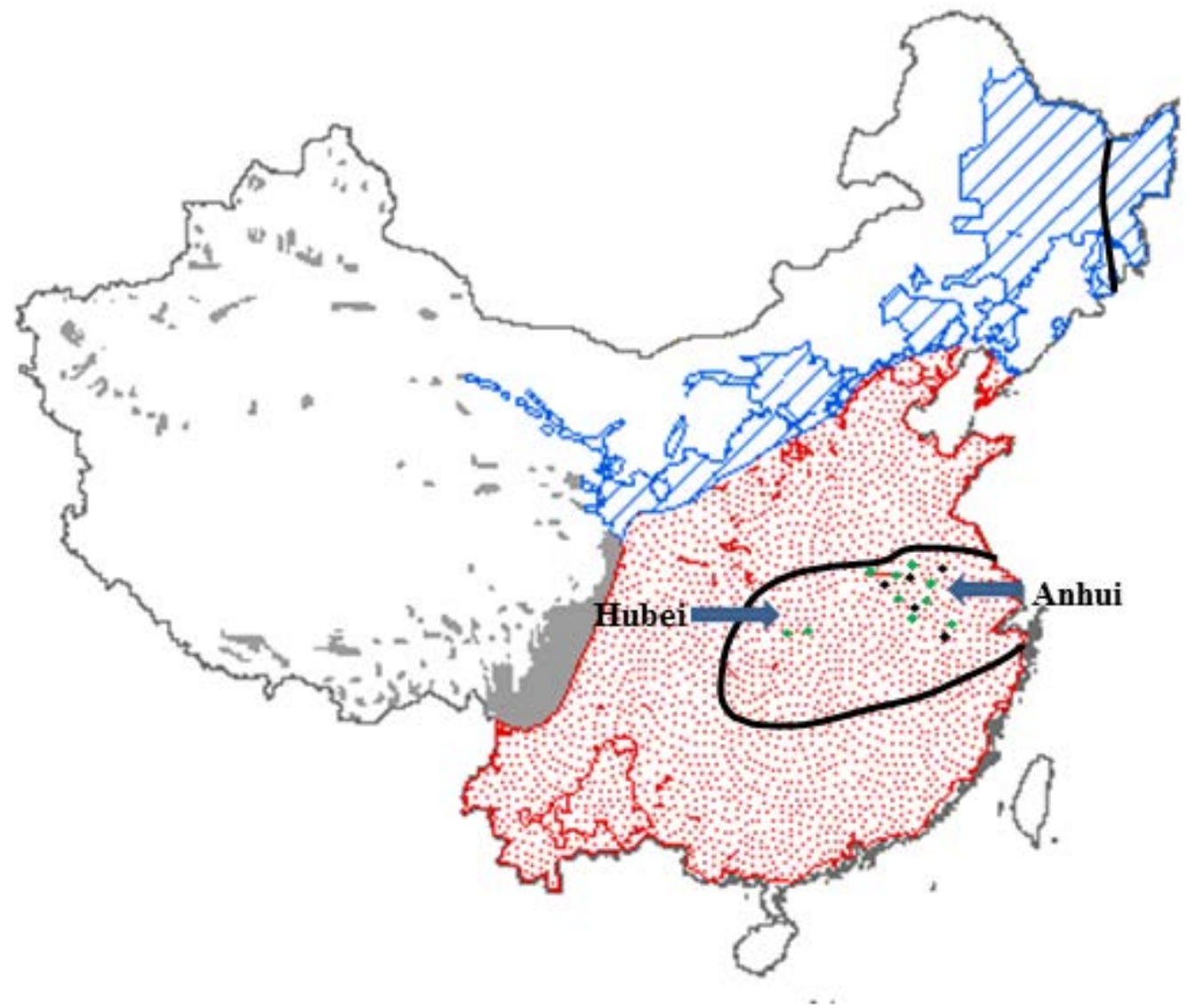

Figure 1 


\section{Fusarium and climate change in China}

1. Observed disease incidence, wheat anthesis date and weather data

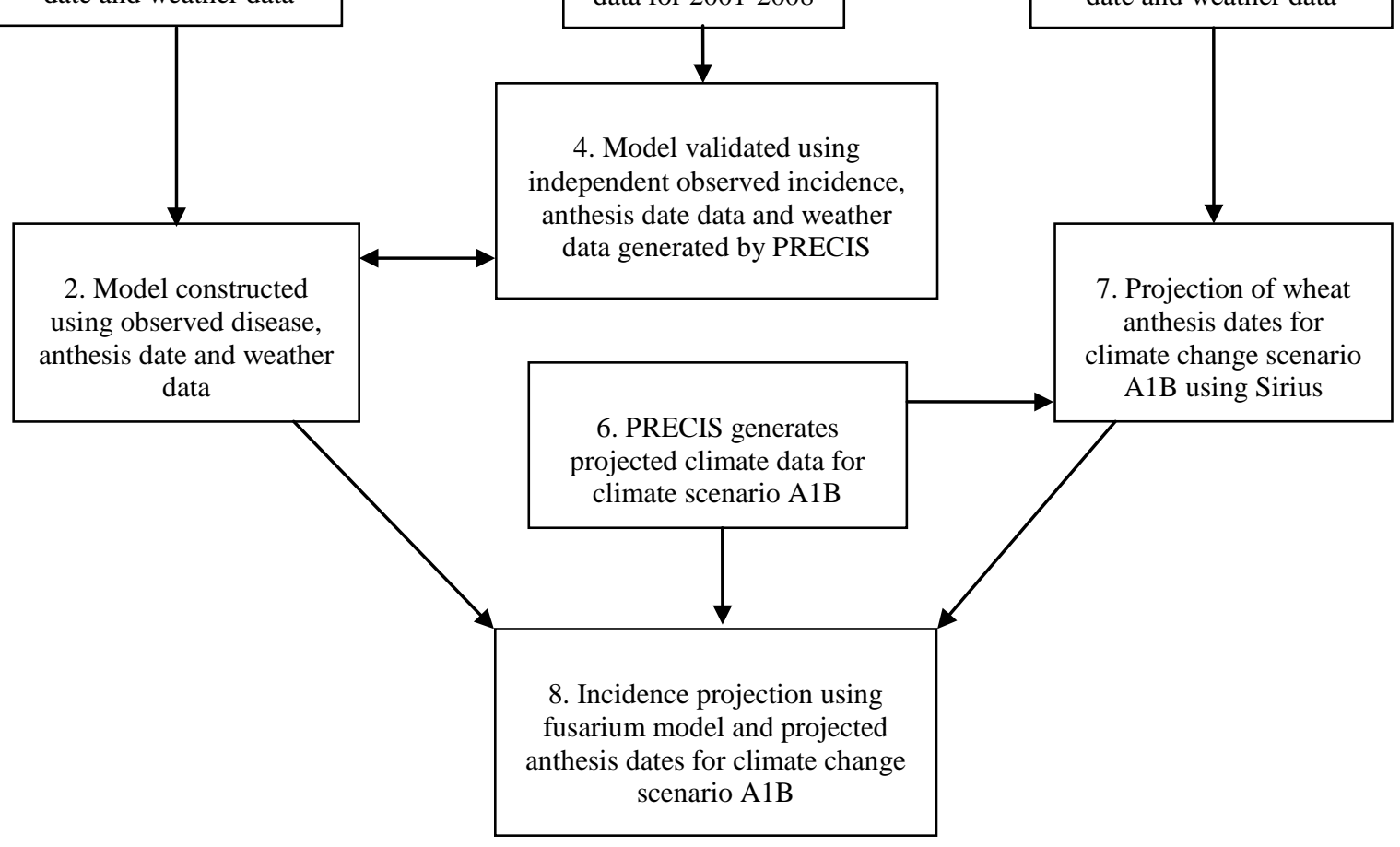

5. Calibration of Sirius using observed anthesis date and weather data generates weather generates weather

Figure 2

. 
Fusarium and climate change in China

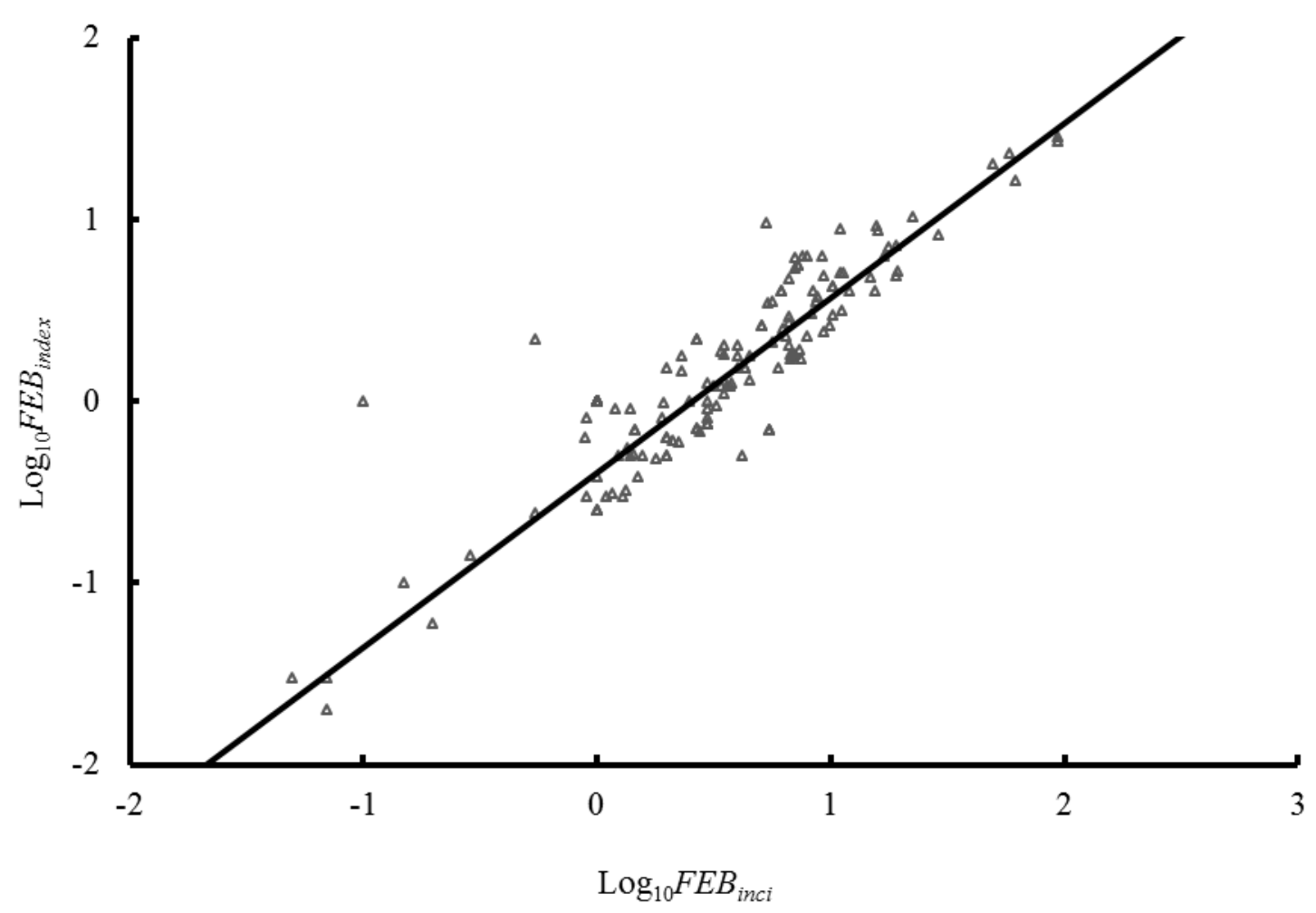

Figure 3 
Fusarium and climate change in China

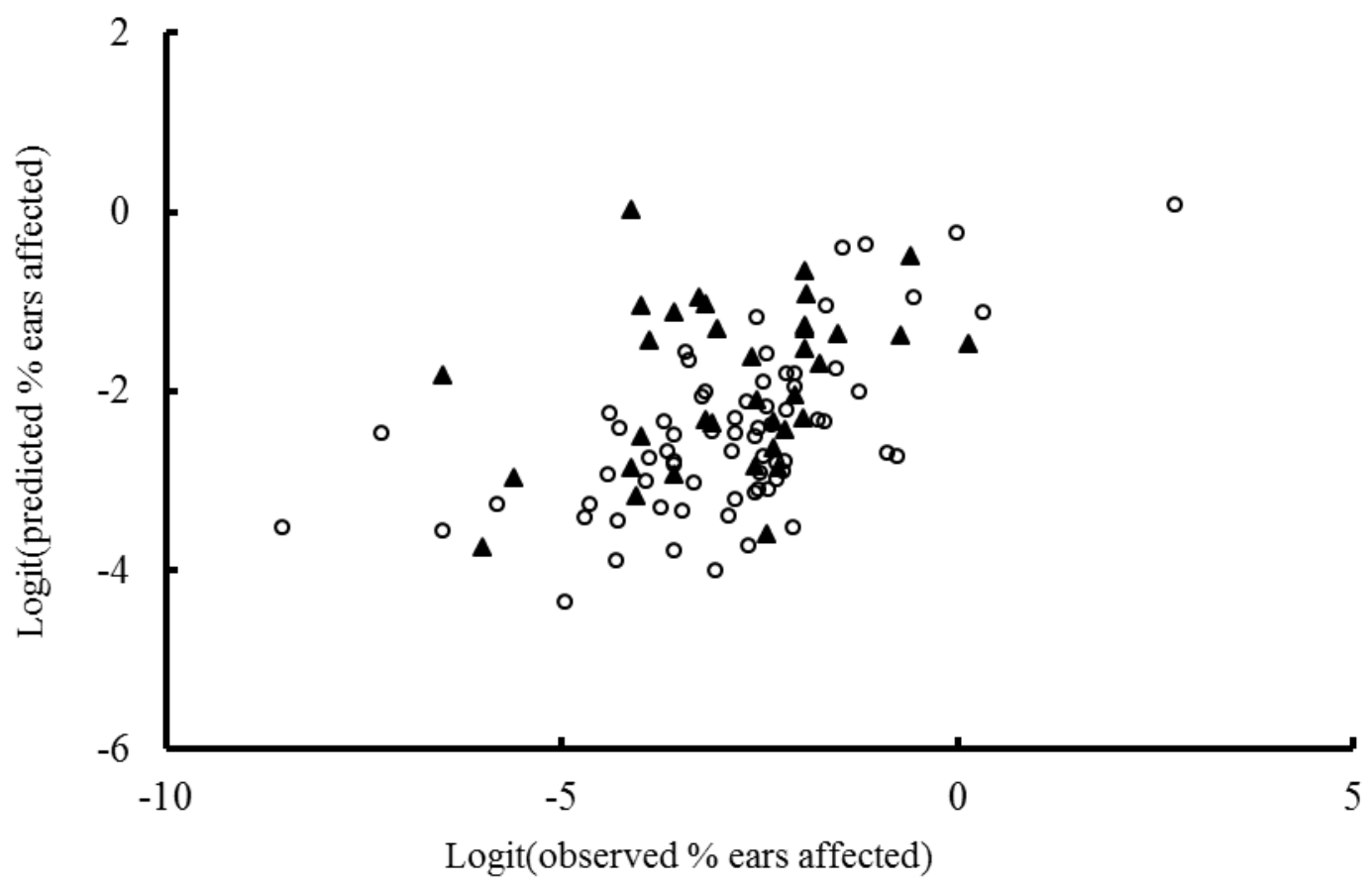

Figure 4 


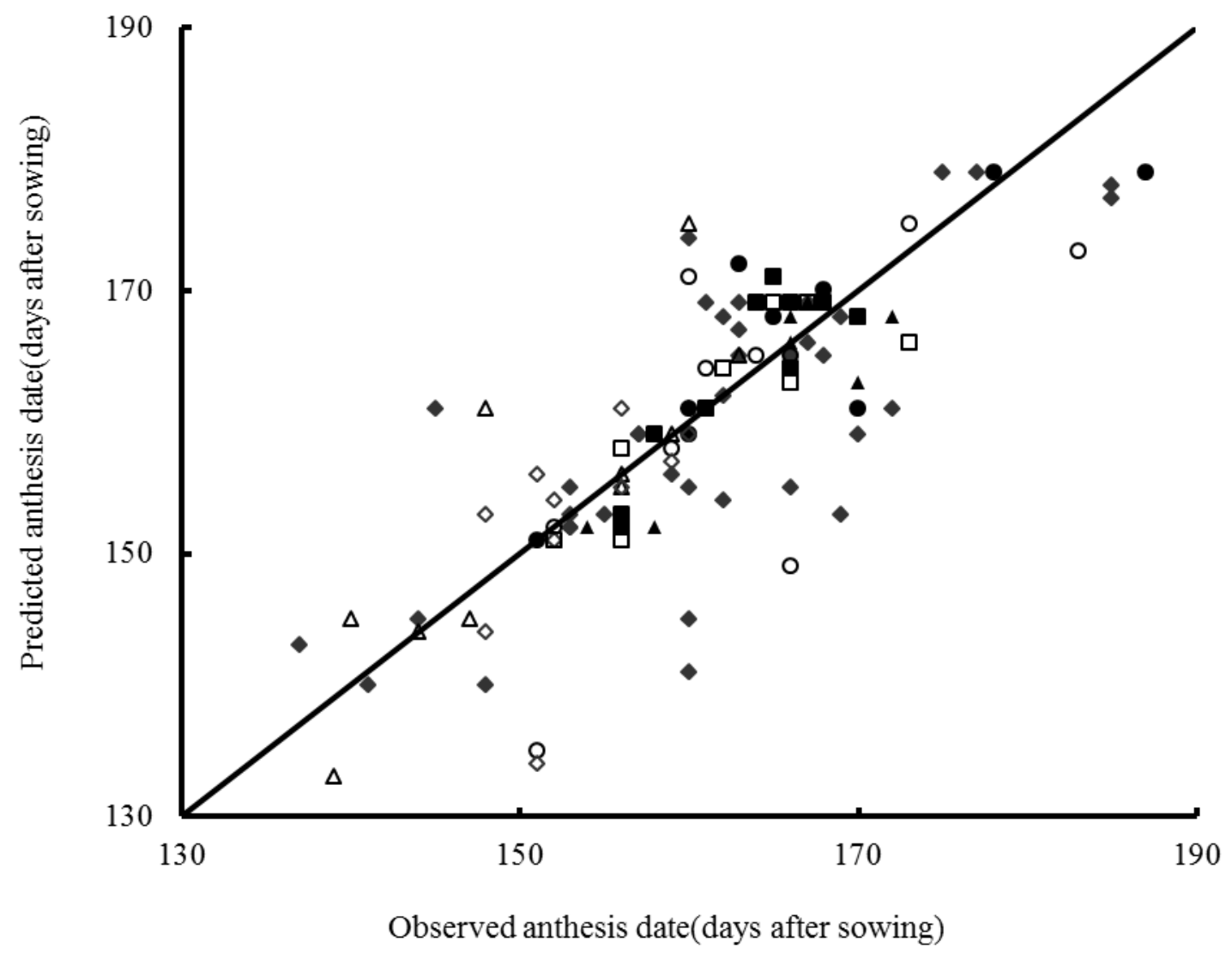

Figure 5 


\section{Fusarium and climate change in China}

(a)

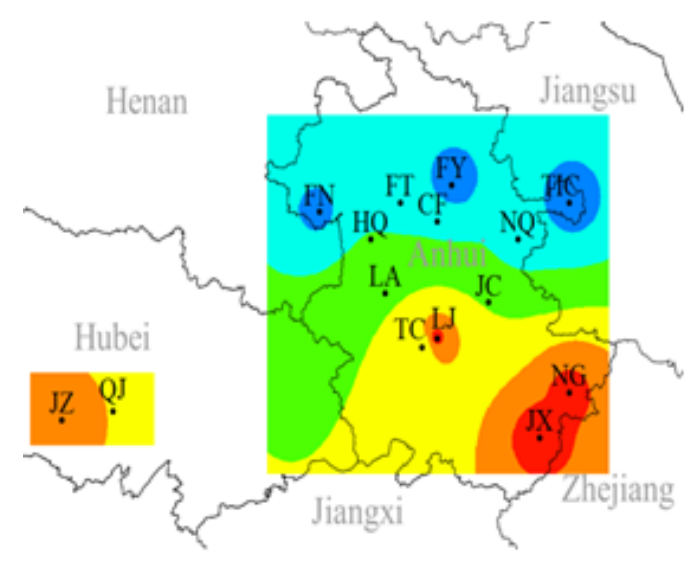

(b)

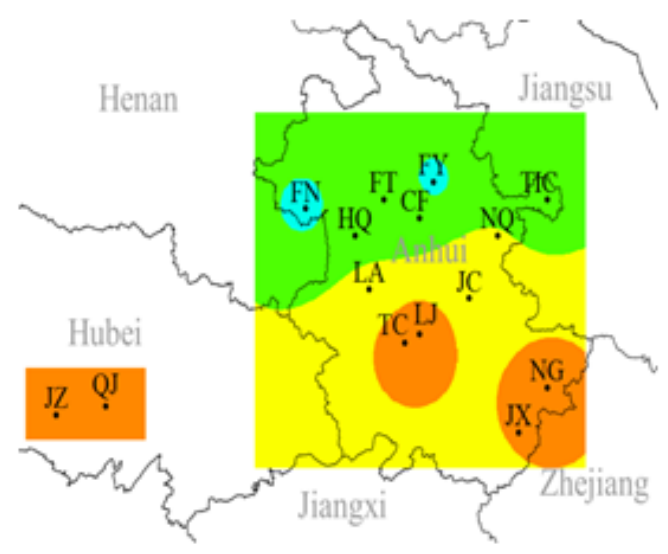

Date of anthesis (April)

\begin{tabular}{l|l|l|l|l|l|l|l|l|}
$<6$ & $6-9$ & $9-12$ & $12-15$ & $15-18$
\end{tabular}

Figure 6 
Fusarium and climate change in China

(a)

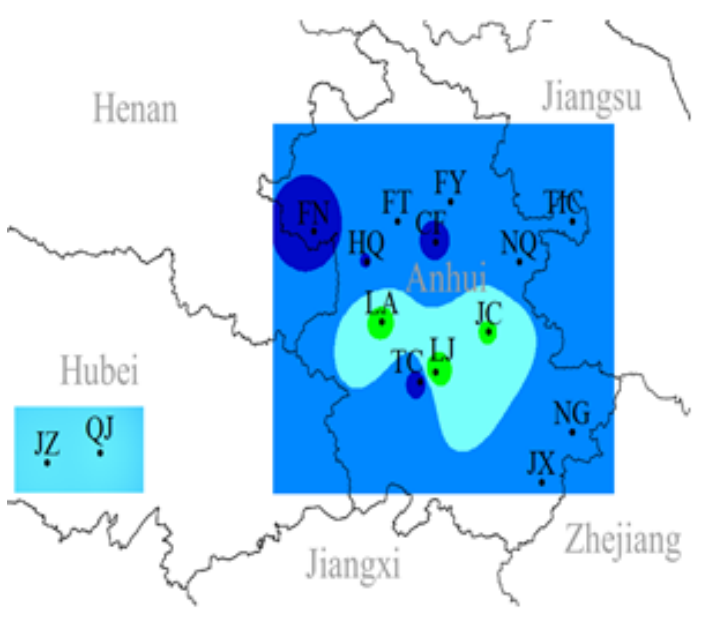

(b)

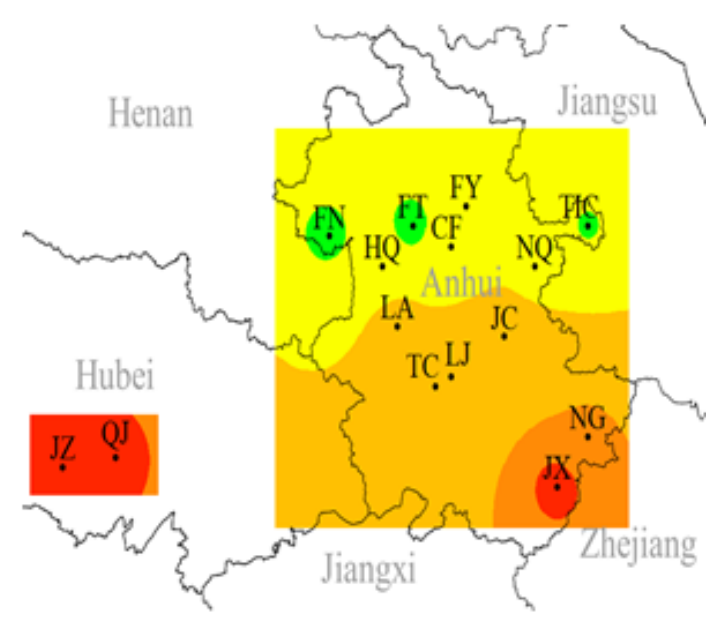

$\%$ ears with fusarium ear blight

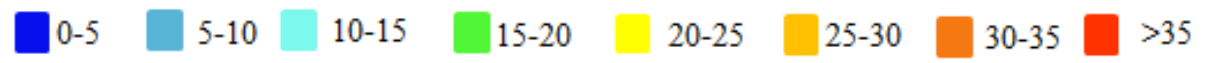

Figure 7 